\title{
Predation release of Texas horned lizards (Phrynosoma cornutum) living in small towns
}

\author{
Stephen Mirkin ${ }^{1}$, Mary Tucker $^{1}$, and Dean A. Williams ${ }^{2}$ \\ ${ }^{1}$ Texas Christian University College of Science and Engineering \\ ${ }^{2}$ Texas Christian Univ
}

October 30, 2020

\begin{abstract}
Texas horned lizards (Phrynosoma cornutum) have a number of ways to avoid predation, including camouflage, sharp cranial horns, flattening of the body, and the ability to squirt blood from the eyes. These characteristics and their relatively low survival rates in the wild suggests these lizards are under high predation pressure. These lizards have been declining in much of their eastern range due to increased urbanization, agriculture, and loss of prey species. However, they can be still be found in some small south Texas towns where they can reach densities that are much higher ( 50 lizards/ha) than in natural areas ( 4-10 lizards/ha). We hypothesized that one reason for the high densities observed in these towns may be due to reduced predation pressure. We used model Texas horned lizards to test whether predation levels were lower in two south Texas towns than on a nearby ranch. We constructed models from urethane foam, a material that is ideal for preserving marks left behind by predators. Models $(\mathrm{n}=126)$ and control pieces of foam $(\mathrm{n}=21)$ were left in the field for 9 days in each location in early and late summer and subsequent predation marks were categorized by predator taxa. We observed significantly more predation attempts on the models than on controls and significantly fewer attempts in town $(\mathrm{n}=1)$ compared to the ranch $(\mathrm{n}=60)$. On the ranch, avian predation attempts appear to be common especially when the models did not match the color of the soil. Our results suggest that human modified environments that have suitable habitat and food resources may provide a refuge for some prey species like horned lizards from predators.
\end{abstract}

Predation release of Texas horned lizards (Phrynosoma cornutum ) living in small towns

Stephen Mirkin ${ }^{1 *}$, Mary R. Tucker ${ }^{2}$, Dean A. Williams ${ }^{3}$

${ }^{1}$ Department of Biology, Texas Christian University, Fort Worth, TX

${ }^{*}$ Corresponding author

Abstract: Texas horned lizards (Phrynosoma cornutum ) have a number of ways to avoid predation, including camouflage, sharp cranial horns, flattening of the body, and the ability to squirt blood from the eyes. These characteristics and their relatively low survival rates in the wild suggests these lizards are under high predation pressure. These lizards have been declining in much of their eastern range due to increased urbanization, agriculture, and loss of prey species. However, they can be still be found in some small south Texas towns where they can reach densities that are much higher ( $\sim 50$ lizards/ha) than in natural areas ( 4 -10 lizards/ha). We hypothesized that one reason for the high densities observed in these towns may be due to reduced predation pressure. We used model Texas horned lizards to test whether predation levels were lower in two south Texas towns than on a nearby ranch. We constructed models from urethane foam, a material that is ideal for preserving marks left behind by predators. Models $(\mathrm{n}=126)$ and control pieces of foam $(\mathrm{n}=21)$ were left in the field for 9 days in each location in early and late summer and subsequent predation marks were categorized by predator taxa. We observed significantly more predation attempts on the models than on controls and significantly fewer attempts in town $(\mathrm{n}=1)$ compared to the ranch $(\mathrm{n}=60)$. 
On the ranch, avian predation attempts appear to be common especially when the models did not match the color of the soil. Our results suggest that human modified environments that have suitable habitat and food resources may provide a refuge for some prey species like horned lizards from predators.

\section{INTRODUCTION}

Interactions between predators and prey are rarely observed in nature, making it inherently difficult to understand the effect that predators have on the population sizes of prey species. Nevertheless, predation has historically been of interest to biologists and is thought to be one of the most influential ecological processes governing community structure (Lima 1998, Sih et al. 1998, Shochat et al. 2006). Top down effects of predators on their prey are well documented and are thought to be in part responsible for densities of prey species at lower trophic levels (Newton 1998, Marzluf 2001). Removal of certain keystone predators like wolves (Canis lupus ) in Yellowstone National Park, can even impact entire communities and landscapes (Fortin et al. 2005). With natural habitats being increasingly altered by human development, an important conservation question, now and in the future, will be to determine how predation affects the structure and assemblages of urban communities.

Urbanization is a major factor in the loss of biodiversity worldwide (Czech and Krausman 1997, Wilcove et al. 1998, McKinney 2008). Altered community structure is a hallmark of urban environments; urban communities can differ greatly from their natural counterparts with some species able to adapt while others decline (Fischer et al. 2012). The role that predation plays in structuring urban communities is not well understood, but has been suggested to be similar to what is found in natural areas (Shochat et al. 2006). Increasing evidence, however, indicates that predation may act differently in urban environments, leading to what authors have termed an urban predation paradox (Fischer et al. 2012, Eötvös et al. 2018). Studies done largely on urban birds and mammals have shown that urban environments have high densities of mesopredators, but paradoxically lower rates of predation (Fischer et al. 2012, Eötvös et al. 2018). Lower predation rates in urban environments have been attributed to predators subsisting mainly on anthropogenic subsidies (i.e. trash and domestic pet food) (Rodewald et al. 2011). Subsequently, prey species in urban areas may experience an ecological release and lower predation rates that can allow them to exist in hyperabundance (Fischer et al. 2012). Alternatively, some research has shown that predators are more sensitive to urbanization and are pushed out of urban areas because of a lack of suitable habitat. Consequently, urban environments may act as refugia for some prey species due to the lack of predators in those areas (Berger 2007, Leighton et al. 2010, Muhly et al. 2011, Shannon et al. 2014, Rebolo-Ifran et al. 2017).

Few studies have been conducted on the impact that predation has on reptiles living in urban environments, and results from these are often conflicting (French et al. 2018). Species richness and abundance are generally negatively correlated with urbanization (Mckinney 2008); however, some studies show that reptiles thrive in urban environments and even increase in abundance and diversity under certain conditions (Schlauch 1978, Moreno-Rueda and Pizaarro 2007, Barret and Guyer 2008). Due to the difficulty in observing predation events, many researchers have turned to the use of clay or foam models to measure predation (Bateman et al. 2016). Of these studies, only Mcmillan and Irshick, (2010) explicitly tested differences in predation rates between urban and natural environments. Their results, consistent with the urban predation paradox, showed significantly lower amounts of predation on green anole models (Anolis carolinensis) in the urban area.

Texas horned lizards (Phrynosoma cornutum) are highly specialized lizards with unique morphological characteristics and dietary preferences and exhibit a variety of adaptations for life as myrmecophagus, sitand-wait predators, living in arid environments (Pianka and Parker 1975, Sherbrooke 2003). Many of these behavioral and morphological adaptations can be attributed to selective forces in response to predation (Edmunds, 1974, Endler, 1986) and include: cryptic coloration, cranial horns, blood squirting, and specific behaviors in response to distinct predators (Pianka and Parker 1975, Sherbrooke 1987, Middendorf III and Sherbrooke 1992, Sherbrooke 2008). Texas horned lizards are known to have a multitude of predators including: snakes, predatory lizards, birds, rodents, canids, and felids (Sherbrooke 2003). Their low annual survival rate (8.9-54\%) is also often attributed to high predation pressure (Fair and Henke 1999, Endriss et 
al. 2007, Miller et al. 2020).

Texas horned lizards, an iconic vertebrate of the American southwest, have declined, especially in eastern areas of their historic range and are now a threatened species in the state of Texas (Donaldson et al. 1994, Texas Conservation Action Plan - TCAP 2012). Declines in these once common lizards are attributed to a variety of factors including: urbanization and habitat conversion, invasive red fire ants (Solenopsis invicta), which can prey on the eggs and young of horned lizards, the loss of harvester ants (Pogonomyrmex spp) due to widespread use of insecticides and competition with fire ants, and over-collecting for the pet and curio trades (Donaldson et al. 1994, Henke 2003). Texas horned lizards are still found in some small Texas towns, including populations occurring in the towns of Kenedy and Karnes City in southern Texas. Past research has shown that lizards in these towns occur at average densities of 52.32 $\pm 11.2 \mathrm{SE}$ lizards/ha (Ackel 2015), which is much higher than the reported densities in more natural areas (3-10 lizards/ha) (Whitford and Bryant 1979, Whiting et al. 1993). Lizards in these towns predominately eat smaller ants (Pheidole spp.) and termites (Tenuirostritermes cinereus ) rather than their commonly preferred prey of large harvester ants (Alenius 2018). Foraging on smaller prey items may increase handling time for Texas horned lizards, which would put them at higher risk of predation; therefore, we hypothesized that predation rates are lower in town than in more natural areas, and that this has facilitated both high densities of lizards and the exploitation of small prey items.

In this study we created foam models of hatchling, juvenile, and adult Texas horned lizards and placed them in small towns and a natural habitat to test the hypothesis that predation rates would be lower in town. Our goal was to create morphologically accurate models, that when placed on the landscape, would sample a variety of predators of Texas horned lizards. Specifically, we asked: 1) do predation attempts on foam models differ between urban and natural areas?; and 2) do hatchling, juvenile, and adult Texas horned lizard models differ in their number of predation attempts?

\section{METHODS}

\section{Field Sites:}

We placed models in three locations: Kenedy and Karnes City in Karnes County, Texas served as urban environments, whereas a private 1,200-ha hunting ranch in Dimmit County, Texas served as a natural habitat. Karnes City and Kenedy are two small towns (3,299 - 3,337 people) known for having Texas horned lizards, and are the sites of ongoing studies. We have censused 15-17 study plots in Kenedy ( $3-4$ study plots) and Karnes City (12 - 13 study plots) since 2013 (Wall 2014, Ackel 2015, Alenius 2018). The study plots are irregular in shape, range from 0.054 to 1.22 ha, and represent a variety of suburban habitat types such as alleyways, school yards, vacant lots, parks, and residential areas. Vegetation at all sites consisted of native herbs (especially lamb's-quarters, Chenopodium album ; straggler daisy, Calyptocarpus vialis ; threelobed false mallow, Malvastrum coromandelianum ; and tropical amaranth, Amaranthus polygonoides ) and grasses (tumble windmill grass, Chloris verticillata ; plains bristle grass Setaria vulpiseta) and the nonnative Bermuda grass (Cynodon dactylon). Honey mesquite (Prosopis glandulosa), anacua (Ehretia anacua ), and sugar hackberry (Celtis laevigata) are the most common trees on the study plots (Wall 2014). Each site is surveyed $8-10$ times between the end of May and mid-August. During each survey, we walk linear transects with 2-5 people, spaced 2 meters apart, until we search the entire area of the site. Surveys typically last 20 minutes to 2.5 hours, and are conducted between 0800-1200 and 1600-2000, during active periods for Texas horned lizards (Moeller et al. 2005).

Over the course of six field seasons (2013-2018), predator observations in and adjacent to our study plots, include frequent (daily or weekly) sightings of cats (Felis catus), dogs (Canis lupus familiaris), and northern raccoons (Procyon lotor). We have found very few snakes, including Texas rat snakes (Elaphe obsoleta lindheimeri) ( $\mathrm{n}=4$ sightings), coachwhips (Masticophis flagellum ) ( $\mathrm{n}=1$ sighting), bull snakes (Pituophis catenifer sayi ) ( $\mathrm{n}=1$ sighting). Predatory birds are also rarely seen, red-tailed hawks (Buteo jamaicensis ) ( $\mathrm{n}=3$ sightings), greater roadrunners (Geococcyx californianus ) ( $\mathrm{n}=2$ sightings).

The Dimmit County ranch located within the South Texas Plains ecoregion is approximately $32 \mathrm{~km}$ North 
of the Chapparal WMA (wildlife management area). The habitat is dominated by honey mesquite (Prosopis glandulosa ) and Acacia thornscrub communities typical of south Texas shrubland. This relatively wild habitat maintains natural communities of both predators and prey for Texas horned lizards making it an ideal site for monitoring natural predation on these lizards. Our ad hoc observations of predators on the ranch during the summer of 2018, included a number of potential predators of Texas horned lizards including: Harris hawk (Parabuteo unicinctus), red-tailed hawk, Swainson's hawk (Buteo swainsoni), American kestrel (Falco sparverius), greater roadrunners, and loggerhead shrikes (Lanius ludovicianus), western diamondback rattlesnake (Crotalus atrox), bull snake, Texas indigo snake (Drymarchon melanurus erebennus), bobcat (Lynx rufus), coyote (Canis latrans), and northern grasshopper mice (Onychomys leucogaster ).

\section{Model Construction:}

We constructed horned lizard models and controls using urethane foam, a material that has proven effective at withstanding Texas summertime temperatures in excess of $38^{\circ} \mathrm{C}$ and preserving marks left behind by predation (Farallo and Forstner 2012). We constructed molds using Mold Max 29NV@ silicone rubber (Smooth-On) and a pewter replica of an adult Texas horned lizard (84 mm snout-to-vent length, SVL). The original pewter horned lizard replica was scanned to create an object file (.obj) that was used to 3D print three size classes of model Texas horned lizards: hatchling (23 mm SVL), juvenile (50 mm SVL), and adult ( $84 \mathrm{~mm}$ SVL) size models. We used these 3D printed models to create molds capable of producing the different size classes used in this study and multiple models per casting. Foam iT! $3 \AA$ urethane foam (Smooth-On) was poured into the molds and allowed to cure for 2 hours. The controls were constructed from round pieces of urethane foam left over from casting the lizard models and painted with acrylic paint and otherwise treated exactly like the lizard models to control for predators being attracted to the foam material or to the paint (Fig. 1).

We painted models and control pieces using acrylic paint to match two distinct color variations of Texas horned lizards (Fig. 1); gray lizards from the urban environments of Kenedy and Karnes City where the substrate is varied but predominately gray in color, and red colored lizards from a population found in the natural ranch setting in Dimmit County where the substrate is characterized largely by red soils. The specific colors of the models were determined using photographs of multiple adult Texas horned lizards from each location where models were placed, as well as from photographs taken of the surrounding substrates. The PANTONE Studio app (X-Rite) for iPhone was used to take photos of the substrates where lizards were previously found to select colors for the models that would accurately resemble local lizards, as well as, background color-match the substrates. After painting, we placed dried models outside and covered them with a loose layer of soil to allow paint fumes to dissipate for a period of 7 days prior to placing them in the field.

\section{Predation Experiment:}

We placed 6 models of each size class (hatchlings, juveniles, adults) and 3 controls across 7 sites in town and 7 sites on the ranch for a total of 126 models and 21 control pieces in both habitat types. The 7 sites in Kenedy and Karnes City included yards, vacant lots, alley-ways, and school playgrounds in areas that contained horned lizards determined from previous surveys. The 7 sites of model placement on the ranch included areas with known Texas horned lizard activity as determined by surveys for lizards and their scat. Models were secured to the substrate using 2 inch nails with the nail head painted over to cover the metallic surface.

We conducted experiments during two time intervals: 9-June-2018 to 29-June-2018 and 4-August-2018 to 21-August-2018. During the first nine days of each time period, models were placed in the urban environment and then were subsequently relocated to the natural ranch setting for nine days. We used these two time periods (early and late summer) to account for differences in weather and possibly predation. During the early summer, round models were painted to color-match the substrate and lizards in the urban environment. During the late summer, models were repainted to color-match the red soils and lizards that were found on the ranch in Dimmit County. This experimental design allowed us to test for any differences in predation 
rates due to background color-matching between models and the substrate upon which they were placed.

Upon initial deployment, we recorded the coordinates of each model using the Collector for ArcGIS app (ESRI) with 1-m accuracy. We also photographed models upon initial placement and upon discovering a potential predation event or disturbance with a Nikon d3300 digital SLR camera with a Tamron 16-300mm lens. We checked models every three days during the 9 day period and models that had evidence of predation or disturbance were photographed and removed. We used similar criterion as Brodie, (1993) and Bittner, (2003) when categorizing predation events. Predation marks on the models were categorized into 4 categories: Birds-obvious "V" or "U" shaped peck marks and models that had been decapitated; Rodents- bite marks with distinguishable chisel teeth imprints left on the model; Other- bites that left distinct half-moon shaped impressions on both upper and lower sides of the model; or Unknown- models that had limbs removed but no clear bite or peck marks and models that were found in multiple pieces (Fig. 2).

\section{Color-Matching:}

To test whether models were successfully painted to color-match their surrounding substrates we photographed each model in the field with a ColorChecker Passport Photo with software version 1.1.2 (X-Rite Inc. Grand Rapids, MI 49512, USA) in the frame. Using this color standard and the ColorChecker camera calibration software plugin for Adobe Lightroom Classic, we created digital negative (DNG) profiles that could then be used to create images that were calibrated to their true colors, making it possible to compare color values across all photos. After calibration, a portion of the model lizard's coloration was cropped from the photo using ImageJ and compared with an exact sized crop of substrate adjacent $(\sim 1 \mathrm{~cm})$ to the model. RGB (red, green, blue) color values were obtained from each cropped photo using the Color Inspector 3D v. 2.3, plugin for ImageJ. These color values were then used to create a color overlapping index (COI) using the COI Function in Rstudio (Samia and Francini 2015). We calculated COI scores, indicating the percent color-match between substrate and model, for 40 models.

Statistical Analysis:

For our predation experiment we compared differences in predation rates of models placed in urban and natural environments using Chi-square tests when the assumptions of that test were met. Where the assumptions of Chi-square tests were not met (i.e. expected values of 0) data were then analyzed using Fisher's exact tests. We used two-sample t-tests to determine differences in color-matching between models and checked for differences between urban gray and urban red models and ranch gray and ranch red models.

\section{RESULTS}

Models that were painted to color-match in the urban environment had higher COI scores than those that were not color-matched (urban gray vs urban red, $\mathrm{t}=2.59$, $\mathrm{df}=18, \mathrm{P}=0.019$ ), and models that were painted to color-match on the ranch had higher COI scores than those that were not color-matched (ranch gray vs ranch red), $(\mathrm{t}=4.86, \mathrm{df}=18, \mathrm{P}=0.00013)$ (Fig. 3).

A total of 61 predation events were recorded over both sampling periods representing $12.1 \%$ of all models. We found no difference in the total number of predation events occurring between early summer $(\mathrm{N}=30)$ and late summer $(\mathrm{N}=31)(\mathrm{P}=0.89)$ (Table 1). Four predation events occurred on the controls over both sampling periods, all of which were located on the ranch. Predation events were higher on the models than on the controls, both overall $\left(\chi^{2}=3.74, \mathrm{df}=1, \mathrm{P}=0.05\right)$ and on the ranch $\left(\chi^{2}=3.24, \mathrm{df}=1, \mathrm{P}=0.04\right)$. We observed more predation events on models at the ranch $(\mathrm{N}=60)$ over the two sampling periods than in the towns $(\mathrm{N}=1)\left(\mathrm{P}=1.12 \times 10^{-18}\right)$ (Table 1$)$. During the early summer, 1 model was attacked in town and 29 were attacked on the ranch $\left(\mathrm{P}=1.05 \times 10^{-8}\right)$ (Table 1). During the late summer, no models were attacked in town and 31 were attacked on the ranch $\left(\mathrm{P}=1.13 \times 10^{-10}\right)$. Hatchling models were attacked less than juvenile or adult models $\left(\chi^{2}=7.08, \mathrm{df}=2, \mathrm{P}=0.029\right)$ (Table 1$)$. Models that had evidence of being disturbed by non-predators (i.e. hoof marks) $(n=2)$ or went missing $(n=6)$ were only on the ranch and were not counted as predation events and excluded from the analysis. 
We found a significant difference in the number of predation events by predation category: birds, rodent, other, and unknown $\left(\chi^{2}=33.24, \mathrm{df}=3, \mathrm{P}=2.86 \times 10^{-7}\right)$ (Fig. 4). We also found that the number of attacks by birds in the early summer $(\mathrm{N}=13)$, when lizard models were not painted to color-match the red soils on the ranch was significantly higher than during late summer $(\mathrm{N}=5)$ when models were painted to background color-match $\left(\chi^{2}=3.8, \mathrm{df}=1, \mathrm{P}=0.05\right)$ (Fig. 4). We did not see any difference in color-matching in the remaining categories on the ranch rodents: $\left(\chi^{2}=2.9, \mathrm{df}=1, \mathrm{P}=0.09\right)$, other $\left(\chi^{2}=1.5, \mathrm{df}=1, \mathrm{P}=0.23\right)$ or unknown $\left(\chi^{2}=0.1, \mathrm{df}=1, \mathrm{P}=0.78\right)$ (Fig 4$)$. The attack in June on a control piece had distinct peck marks, whereas the three remaining controls that were attacked in August had conspicuous half-moon shape bite marks (Fig. 5). Our controls during the second round were painted to color-match the soils on the ranch and as a result resembled dried prickly pear (Opuntia spp.) pads and fruits; which may have attracted Texas tortoises (Gopherus berlandieri) (Fig. 5). We frequently encountered Texas tortoises eating both the fruits and pads of Opuntia spp. on the Dimmit County ranch and the bite marks on the controls were similar in size and shape to the tortoise bites on cactus pads (Fig. 5).

\section{DISCUSSION}

Our results supported our hypothesis that predation on Texas horned lizards in town would be lower than in the natural ranch environment, and are consistent with other studies that have found lower predation in urban areas (Fischer et al. 2012). Although we did not explicitly measure predator densities, there is anecdotal evidence that the predator community in Kenedy and Karnes City differs in both the abundance and diversity of predators when compared to the ranch. For instance, birds of prey and snakes are rarely seen in or near our study plots in the towns but were seen daily at the ranch. Feral and pet cats and dogs are also common in town but do not occur on the ranch. Altered predator communities are a consistent result of urbanization (Prange and Gehrt 2004, Fischer et al. 2012) and relaxed predation pressure in town by certain types of predators like birds may be a contributing factor to the high density of Texas horned lizards in Kenedy and Karnes City (Ackel 2015) and their dietary shift to consuming small prey items (Alenius 2018)

Although the use of models has proven effective at measuring predation in other studies (Brodie 1993, McMilan and Irshick 2010, Vignieri et al. 2010, Farallo and Forstner 2012), a common concern is the confidence with which predation marks left behind on models are accurately categorized. Marks left behind on models by birds were easy to discern by the presence of conspicuous "V" or "U" shaped peck marks. Models that had been decapitated were also categorized as avian predation because birds tend to attack towards the head of their prey (Smith 1973). Avian predators accounted for $30 \%$ of predation events. Bite marks accounted for $21.7 \%$ and were also relatively easy to discern in models. Bites included obvious chisel marks left behind by rodent incisors and half-moon bite impressions on the dorsum and venter of models that were possibly indicative of predatory lizards (Crotophytus reticulatus. ). All other damage to models not falling into those categories were scored as unknown, which represented $48.3 \%$ of recorded predation events. These unknown predation events included models that had limbs removed but no definitive bite or peck marks. Northern grasshopper mice (Onychomys leucogaster ) are known predators of horned lizards (Munger 1986, Endriss et al. 2007) and have been shown to chew the limbs off Texas horned lizards in areas where both are common (Nathan Rains, Texas Parks and Wildlife, pers. comm.). We also found several live adult lizards on the ranch with missing limbs, although it is unknown what caused the loss of limbs. The models with missing limbs may also be the result of a typical greater roadrunner "centrifugal-slam" attack in which the bird grabs a lizard by any limb or tail and smashes it on the ground (Sherbrooke 1990). These results suggest avian predators are a significant threat to Texas horned lizards, which is similar to findings in other studies that show that avian predators like shrikes consume large numbers of horned lizards and may even be responsible for the evolution of increased cranial horn lengths in flat-tailed horned lizards (Phrynosoma mcallii ) (Munger 1986, Young et al. 2004).

Birds are highly visual (Fox et al. 1976) and avian predators of horned lizards may use their visual acuity to find their cryptically colored prey. Our results showed that when models were painted to background color-match their surroundings (i.e. they were more cryptic), avian predation events were significantly less 
likely than when models were not painted to color-match. This supports a long-held hypothesis that crypsis and background color-matching are the primary defensive adaptations for horned lizards against visually oriented predators (Norris and Lowe 1964, Pianka and Parker 1975).

There are inherent limitations in using models for predation studies which include the lack of movement, smell, and lack of appropriate behavioral responses and therefore models sample a subset of predators (Bateman et al. 2016). For instance, we did not expect models to be attacked by snakes because snakes rely on thermal, motion, and olfactory cues to sense prey (de Cock Buning 1983); all of which are not exhibited by model lizards. Similarly, we did not expect models to be attacked by cats since they are often attracted by motion (Ellis and Wells 2008). We set up motion detection video cameras in the urban areas for some models and filmed several instances of cats walking by and ignoring the models. Nevertheless, local residents have told us that sometimes their pet cats will bring dead horned lizards back to the house. Cats are known to be very efficient predators of small reptiles, birds, and mammals in urban areas (Loss and Marra 2017) and stationary model studies may not be well suited to sample these predation events. Another limitation of models may be that predators are attracted to the particular material used to construct the models (Bateman et al. 2016). Our models were attacked significantly more than the controls however, suggesting predators were not simply attracted to the urethane foam or paint used to construct our models. In the future, we recommend that controls be made into shapes (i.e. pyramids) that would offer no visual cues to encourage predation events such as may have occurred by Texas tortoises mistaking them for cactus pads.

Our hatchling models had fewer predation attempts than the juvenile or adult models. This result may indicate that stationary hatchling lizards are less vulnerable to certain types of predation. Conversely the hatchling models were morphologically the least realistic, due to their small size and difficulty in constructing them and predators may therefore simply not have recognized them as potential prey.

Texas horned lizards have declined throughout their historic range and urbanization is often suggested as one of the main drivers of those declines (Donaldson et al. 1994, Endriss et al. 2007, Wolf et al. 2013). This study presents the first data comparing predation of Texas horned lizards in urban and more natural environments, and may serve as a foundation for future studies. Understanding how some horned lizard populations, like those in Kenedy and Karnes City, are able to persist in urban environments may help inform conservation efforts for other populations. If these human modified environments have suitable vegetation and food resources they may in some cases provide a refuge for some prey species from predators (Keehn and Feldman 2018, Law et al. 2020). Our results further suggest that Texas horned lizards in natural environments experience high levels of predation pressure, and should be an important conservation consideration when targeting areas for potential reintroduction. Models may also be used as a conservation tool in the future by placing them in potential reintroduction areas and in areas where they are established prior to the release of Texas horned lizards to gauge the relative predation pressure the reintroduction site might experience. Knowledge of predation and the predator community at potential reintroduction sites may help increase the probability of survival for reintroduced lizards.

\section{DATA ACCESSIBILITY STATEMENT}

All data used in this paper can be found within the text, table, and figures and will also be available in the DRYAD data repository.

\section{ACKNOWLEDGEMENTS}

We thank Mr. Alan Griffin for giving us access to Los Sueños Ranch and his home so that we could complete this project. We thank Heatherjo Breckenridge, Maggie and Truett Hunt, for lodging and hospitality at the 505 in Kenedy and Wade Phelps for help and support of our studies of Texas horned lizards in Karnes County. We also thank Rachel Alenius and Dusty Rhoads for helping with project ideas and making the models. Amanda Hale and Charles Watson gave invaluable suggestions and feedback. This project was funded by grants from the Andrews Institute of Mathematics \& Science Education at TCU, and grants from the TCU Research and Creative Activities Fund. 


\section{REFERENCES}

Ackel, A. 2015. The devil in the details: population estimation for conservation management of Texas horned lizards (Phrynosoma cornutum ). Masters of Science Thesis, Texas Christian University.

Alenius, R. 2018. Diet analysis of Texas horned lizards (Phrynosoma cornutum ). Masters of Science Thesis, Texas Christian University.

Barrett, K., and Guyer, C. 2008. Differential responses of amphibians and reptiles in riparian and stream habitats to land use disturbances in western Georgia, USA. Biological Conservation 141: 2290-300.

Bateman, P.W., Fleming, P.A., and Wolfe, A.K. 2016. A different kind of ecological modelling: the use of clay model organisms to explore predator-prey interactions in vertebrates. Journal of Zoology301: 251-262.

Berger, J. 2007. Fear, human shields and the redistribution of prey and predators in protected areas. Biology Letters 3: 620-623.

Bittner, T.D. 2003. Polymorphic clay models of Thamnophis sirtalis suggest patterns of avian predation. Ohio Journal of Science 103(3): 62-66

Brodie III, E.D. 1993. Differential avoidance of coral snake banded patterns by free-ranging avian predators in Costa Rica. Evolution 47(1): 227-235.

Czech, B. and Krausman, P.R. 1997. Distribution and causation of species endangerment in the United States. Science 277: 1116-1117

de Cock Buning, T. 1983. Thermal sensitivity as a specialization for prey capture and feeding in snakes. American Zoologist 23(2): 363-375.

Donaldson, W., Price, A.H., and Morse, J. 1994. The current status and future prospects of the Texas horned lizard (Phrynosoma cornutum ) in Texas. Texas Journal of Science 46: 97-113.

Edmunds, M. 1974. Defense in Animals: A survey of anti-predator defenses. Longman, New York, New York, U.S.A.

Ellis, S.L. and Wells, D.L. 2008. The influence of visual stimulation on the behaviour of cats housed in a rescue shelter. Applied Animal Behaviour Science, 113(1-3): 166-174.

Endler, J. A. 1986. Defense against predators. Pp. 109-134. In M.E. Feder and G.V. Lauder, Predator Prey Relationships: Perspectives and Approaches from the Study of Lower Vertebrates. University of Chicago Press, Chicago, Illinois, U.S.A.

Endriss, D. A., Hellgren, E. C., Fox, S. F., \& Moody, R. W. 2007. Demography of an urban population of the Texas horned lizard (Phrynosoma cornutum) in central Oklahoma. Herpetologica , 63(3), 320-331.

Eotvos, C.B., Magura, T. and Lovei, G.L. 2018. A meta-analysis indicates reduced predation pressure with increasing urbanization. Landscape and Urban Planning 180: 54-59.

Fair, W.S. and Henke, S.E. 1999. Movements, home ranges, and survival of Texas horned lizards (Phrynosoma cornutum ). Journal of Herpetology 517-525.

Farallo, V.R. and Forstner, M.R. 2012. Predation and the maintenance of color polymorphism in a habitat specialist squamate. PloS One7(1): e30316.

Fischer, J.D., Cleeton, S.H., Lyons, T.P., and Miller, J.R. 2012. Urbanization and the predation paradox: the role of trophic dynamics in structuring vertebrate communities. Bioscience 62: 809-818.

Fortin, D., Beyer, H.L., Boyce, M.S., Smith, D.W., Duchesne, T., and Mao, J.S. 2005. Wolves influence elk movements: behavior shapes a trophic cascade in Yellowstone National Park. Ecology 86: 1320-1330.

Fox, R., Lehmkuhle, S.W., and Westendorf, D.H. 1976. Falcon visual acuity. Science 192(4236): 263-265. 
French, S.S., Webb, A.C., Hudson, S.B., and Virgin, E.E. 2018. Town and country reptiles: a review of reptilian responses to urbanization. Integrative and comparative biology 58: 948-966.

Henke, S.E. 2003. Baseline survey of Texas horned lizards, Phrynosoma cornutum in Texas. The Southwestern Naturalist48:278-282.

Keehn, J.E., and Feldman C.R. 2018. Predator attack rates and anti-predator behavior of side-blotched lizards (Uta stansburiana) at southern California wind farms, USA. Herpetological Conservation and Biology 13:194-204.

Law, C., Lancaster, L., Hale, J., Handy, S., Hinchliffee, M., O'Brien, K., Watts, S., and O'Brien, D. 2020. Quantifying the differences in avian attack rates on reptiles between an infrastructure and a control site. European Journal of Wildlife Research 66: 54.

Lima, S.L. 1998. Nonlethal effects in the ecology of predator-prey interactions. Bioscience 48:25-34.

Leighton, P.A., Horrocks, J.A., and Kramer, D.L. 2010. Conservation and the scarecrow effect: Can human activity benefit threatened species by displacing predators? Biological Conservation 143(9): 2156-2163.

Loss, S.R., and Marra, P.P. 2017. Population impacts of free-ranging domestic cats on mainland vertebrates. Frontiers in Ecology and the Environment 15:502-509.

Marzluff, J.M. 2001. Worldwide urbanization and its effects on birds. Pp 19-47 in Marzluff J.M, Bowman R., Donnelly R., eds. Avian Ecology and Conservation in an Urbanizing World.

McKinney, M.L. 2008. Effects of urbanization on species richness: a review of plants and animals. Urban Ecosystems 11: 161-76.

McMillan, D.M., and Irshick, D.J. 2010. Experimental test of predation and competition pressures on the green anole (Anolis carolinensis ) in varying structural habitats. Journal of Herpetology 44: 272-278.

Middendorf, G.A., and Sherbrooke, W.C. 1992. Canid elicitation of blood-squirting in a horned lizard (Phrynosoma cornutum ).Copeia 1992(2):519-527.

Miller, K.J., Erxleben, D.R., Rains, N.D., Martin, J.C., Mathewson, H.A. and Meik, J.M., 2020. Spatial use and survivorship of translocated wild-caught Texas horned lizards. The Journal of Wildlife Management , 84(1): 118-126.

Moreno-Rueda, G., and Pizarro, M. 2007. The relative influence of climate, environmental heterogeneity, and human population on the distribution of vertebrate species richness in south-eastern Spain.Acta Oecologica 32: $50-58$.

Muhly, T.B., Semeniuk, C., Massolo, A., Hickman, L. and Musiani, M. 2011. Human activity helps prey win the predator-prey space race. PLoS One 6(3): e17050.

Munger, J.C. 1986. Rate of death due to predation for two species of horned lizard, Phrynosoma cornutum and P. modestum . Copeia 1986(3): 820-824.

Newton, I. 1998. Population Limitation in Birds. Academic Press.

Norris, K.S. and Lowe, C.H. 1964. An analysis of background color-matching in amphibians and reptiles. Ecology 45(3): 565-580.

Pianka, E.R., and Parker, W.S. 1975. Ecology of horned lizards: a review with special reference to Phrynosoma platyrhinos . Copeia1975: 141-162.

Prange, S. and Gehrt, S.D. 2004. Changes in mesopredator-community structure in response to urbanization. Canadian Journal of Zoology 82(11): 1804-1817.

Rebolo-Ifran, N., Tella, J.L., and Carrete, M. 2017. Urban conservation hotspots: predation release allows the grassland-specialist burrowing owl to perform better in the city. Scientific Reports 7(1): 3527. 
Rodewald, A.D, Kearns, L.J., and Shustack, D.P. 2011. Anthropogenic resource subsidies decouple predatorprey relationships.Ecological Applications 21: 936-943.

Samia, D.S. and Francini, R.B. 2015. An affordable method to measure animal-background contrast using digital images. International Journal of Fauna and Biological Studies 2: 8-16.

Schlauch, F.C. 1978. Urban geographical ecology of the amphibians and reptiles of Long Island. In: Kirkpatrick CM, editor. Wildlife and people. West Lafayette (IN): Department of Forestry and Natural Resources and the Cooperative Extension Service. Pp. 25-41.

Shannon, G., Cordes, L.S., Hardy, A.R., Angeloni, L.M. and Crooks, K.R. 2014. Behavioral responses associated with a human-mediated predator shelter. PLoS One 9(4): e94630.

Sherbrooke, W.C. 1987. Defensive head posture in horned lizards (Phrynosoma: Sauria: Iguanidae). The Southwestern Naturalist 32(4):512-515.

Sherbrooke, W.C., 1990. Predatory behavior of captive greater roadrunners feeding on horned lizards. The Wilson Bulletin 102(1): 171-174.

Sherbrooke, W.C. 2003. Introduction to horned lizards of North America. University of California Press, Berkeley.

Sherbrooke, W.C. 2008. Antipredator responses by Texas horned lizards to two snake taxa with different foraging and subjugation strategies. Journal of Herpetology 42(1):145-153.

Shochat, E., Warren, P.S, Faeth, S.H, McIntyre, N.E, and Hope D. 2006. From patterns to emerging processes in mechanistic urban ecology. Trends in Ecology and Evolution 21: 186-191.

Sih, A., Englund, G. and Wooster, D. 1998. Emergent impacts of multiple predators on prey. Trends in Ecology \&3 Evolution 13(9): 350-355.

Smith, S.M. 1973. A study of prey-attack behaviour in young loggerhead shrikes, Lanius ludovicianus . Behaviour 113-141.

Texas Parks and Wildlife Department. 2012. Texas Conservation Action Plan 2012-2016: Overview. Editor, Wendy Connaly, Texas Conservation Action Plan Coordinator. Austin, Texas.

Vignieri, S.N., Larson, J.G. and Hoekstra, H.E. 2010. The selective advantage of crypsis in mice. Evolution 64(7): 2153-2158.

Wall, A. 2014. Home range and genetics of Texas horned lizards (Phrynosoma cornutum ) in two small towns in south Texas. Masters of Science Thesis, Texas Christian University.

Whitford, W.G and Bryant, M. 1979. Behavior of a predator and its prey: the horned lizard (Phrynosoma cornutum ) and harvester ants (Pogonomyrmex spp.). Ecology 60: 686-694.

Whiting, M.J, Dixon, J.R, and Murray, R.C. 1993. Spatial distribution of a population of Texas horned lizards (Phrynosoma cornutum : Phrynosomatidae) relative to habitat and prey. The Southwestern Naturalist 38: 150-154.

Wilcove, D.S., Rothstein, D., Dubow, J., Phillips, A., and Losos, E. 1998. Quantifying threats to imperiled species in the United States.Bioscience 48: 607-615.

Young, K.V. and Brodie, E.D. 2004. How the horned lizard got its horns. Science 304(5667): 65-65.

Table 1. Predation events recorded in town and on the Dimmit County ranch for the two sampling periods and by model size class in 2018.

\begin{tabular}{llll}
\hline Predation Experiment & Urban Predation Events & Ranch Predation Events & Total \\
\hline June & $1 / 126$ & $29 / 126$ & $30 / 252$
\end{tabular}




\begin{tabular}{llll}
\hline Predation Experiment & Urban Predation Events & Ranch Predation Events & Total \\
\hline August & $0 / 126$ & 31 & $31 / 252$ \\
Hatchlings & $0 / 42$ & $6 / 42$ & $6 / 84$ \\
Juveniles & $0 / 42$ & $26 / 42$ & $26 / 84$ \\
Adults & $1 / 42$ & $28 / 42$ & $29 / 84$ \\
Controls & $0 / 42$ & $4 / 42$ & $4 / 84$ \\
\hline
\end{tabular}
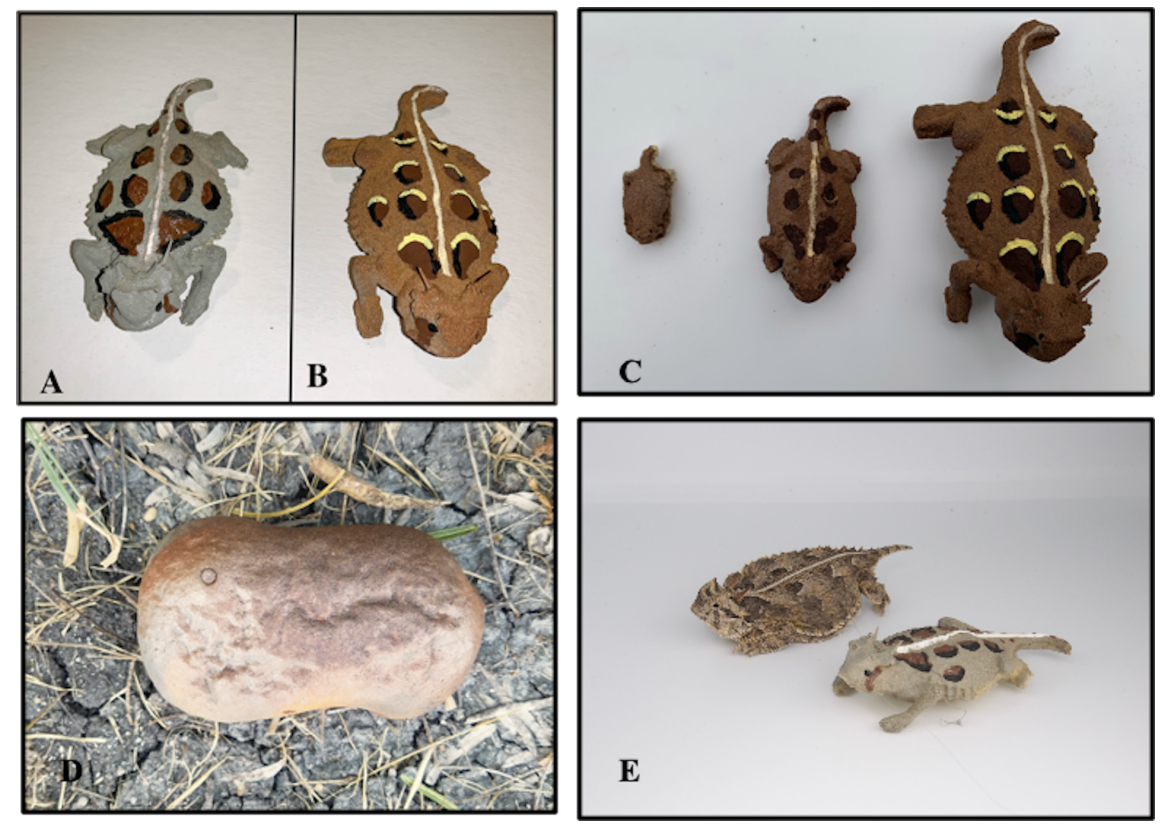

Figure 1. Two distinct color variations of Texas horned lizard models were used in this study. Gray models (A) were painted to match gray lizards found in Kenedy and Karnes City and red models (B) were painted to match Texas horned lizards found on the Dimmit County ranch. We used 3 size classes of models hatchlings, juveniles, and adults (C) and controls (D). Models were created to be as morphologically accurate as possible to mimic actual Texas horned lizards (E).

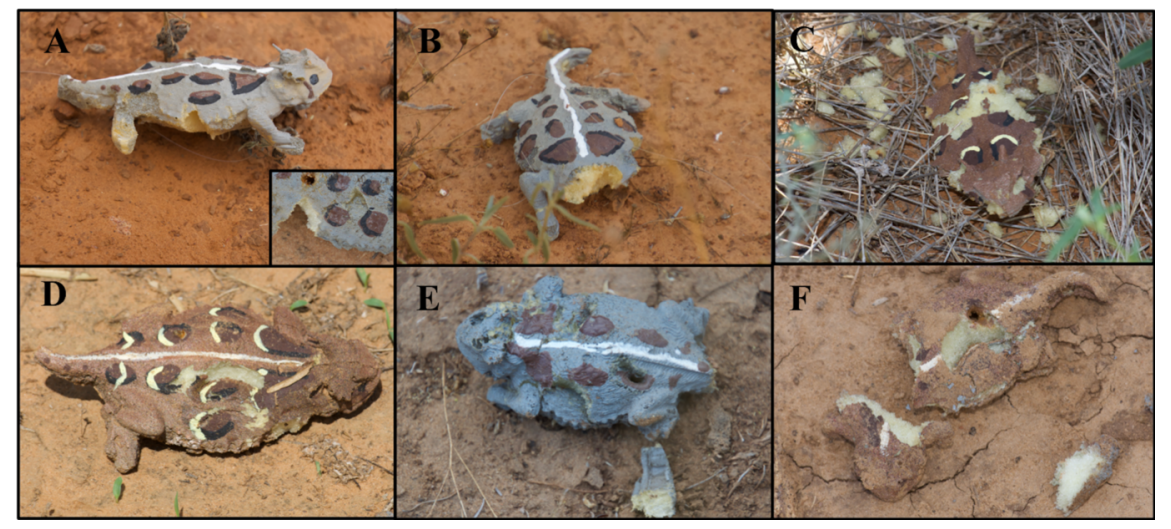

Figure 2. Representative examples of predation events on models attributed to birds (A-Pecks, BDecapitations), Rodents (C), Other (D\&E), and Unknown (F). 


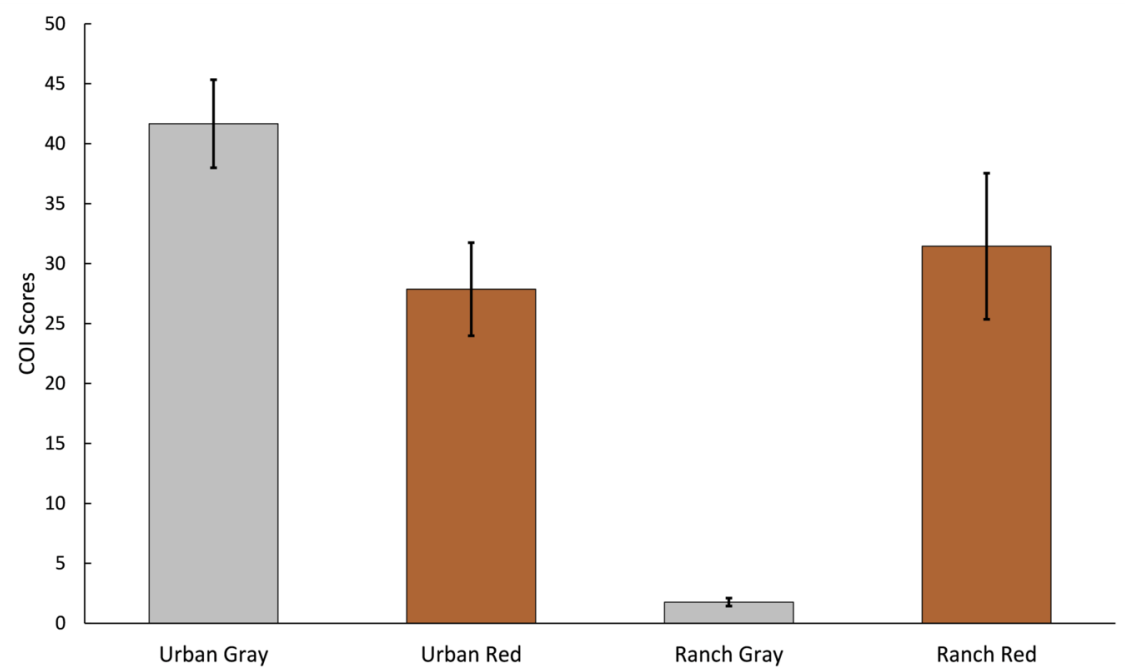

Figure 3. Mean and standard error for COI scores for 10 models in each color-matching scenario. Models that were painted to background color-match their environments have significantly higher COI scores than those that were not painted to match.

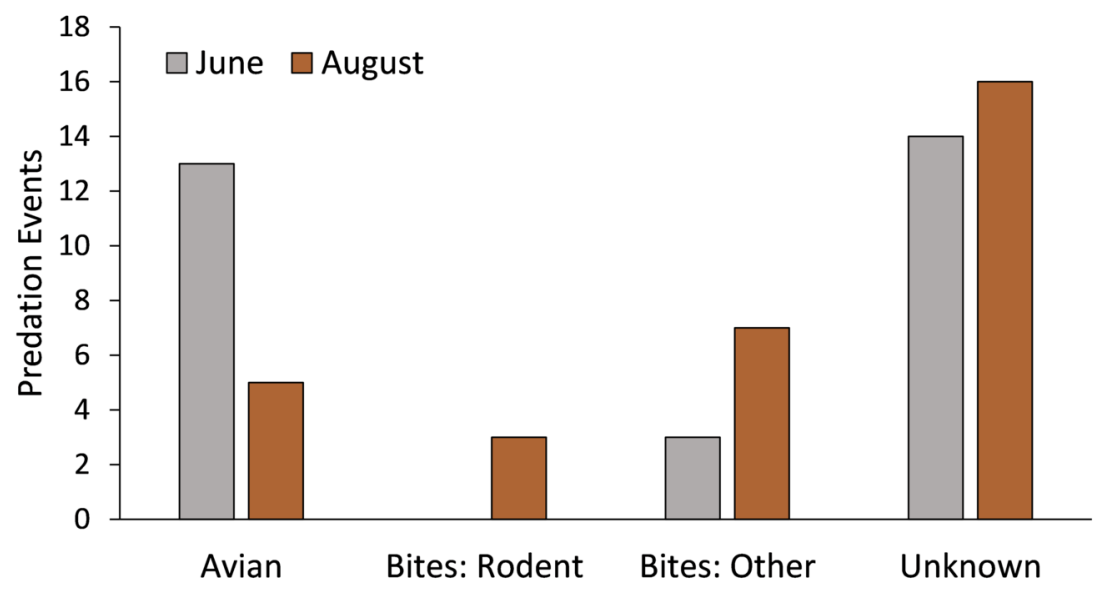

Figure 4. We observed significantly more predation events by avian predators on the ranch when models were not painted to background color-match (i.e. were less cryptic) $(\mathrm{P}=0.05)$, suggesting background colormatching is an important defense mechanism against predators with high visual acuity. We observed no difference in predation events amongst the remaining predation categories. 


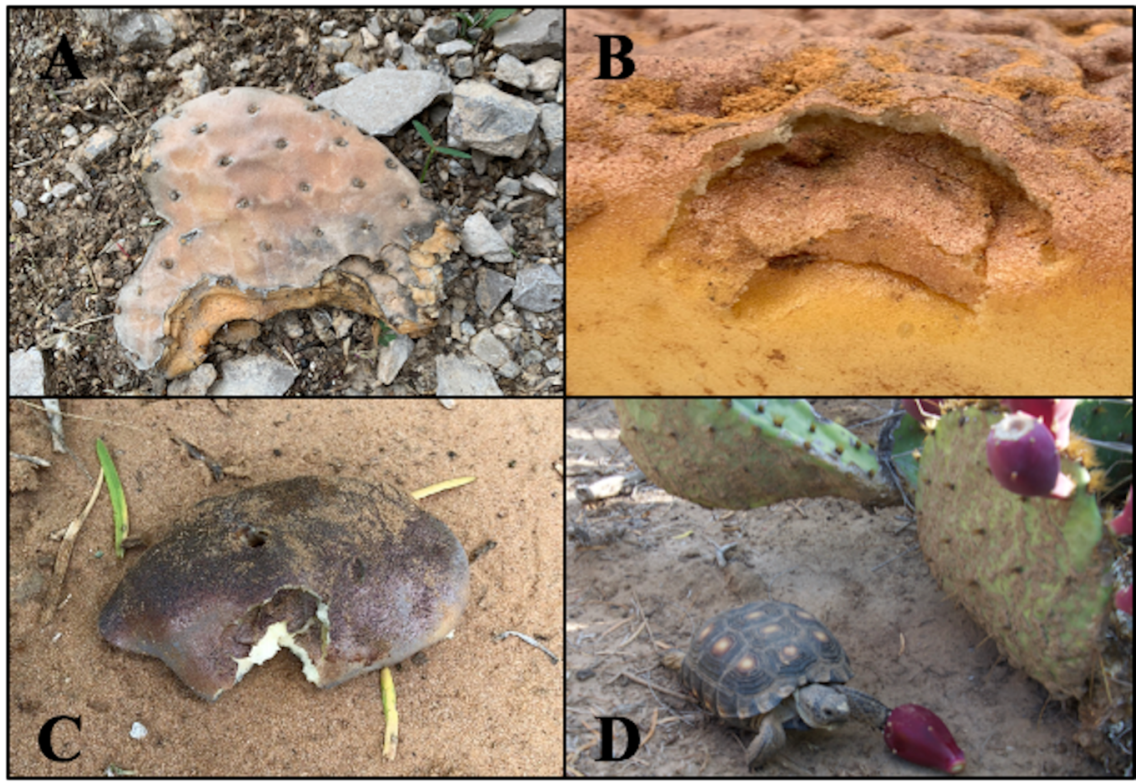

Figure 5. (A) Opuntia spp. pads with bite marks from Texas tortoises (Gopherus berlandieri ) (B\&C) control pieces from late summer in August, 2018 on the Dimmit County ranch with bite marks similar to those in A, (D) Texas tortoises feeding on Opuntiaspp. were a frequent sighting on the Dimmit County ranch. 